\title{
Differential scaling patterns of vertebrae and the evolution of neck length in mammals
}

\author{
Patrick Arnold, ${ }^{1,2,3}$ Eli Amson, ${ }^{4}$ and Martin S. Fischer ${ }^{1}$ \\ ${ }^{1}$ Institut für Spezielle Zoologie und Evolutionsbiologie mit Phyletischem Museum, Friedrich-Schiller-Universität Jena, \\ Erbert-Straße 1, D-07743 Jena, Germany \\ ${ }^{2}$ Department of Human Evolution, Max Planck Institute for Evolutionary Anthropology, Deutscher Platz 6, D-04103 \\ Leipzig, Germany \\ ${ }^{3}$ E-mail: arnold.patrick.zoo@gmail.com
}

${ }^{4}$ AG Morphologie und Formengeschichte, Bild Wissen Gestaltung-ein interdisziplinäres Labor \& Institut für Biologie, Humboldt-Universitat zu Berlin, Philippstraße 12/13, D-10115 Berlin, Germany

Received May 20, 2016

Accepted March 6, 2017

\begin{abstract}
Almost all mammals have seven vertebrae in their cervical spines. This consistency represents one of the most prominent examples of morphological stasis in vertebrae evolution. Hence, the requirements associated with evolutionary modifications of neck length have to be met with a fixed number of vertebrae. It has not been clear whether body size influences the overall length of the cervical spine and its inner organization (i.e., if the mammalian neck is subject to allometry). Here, we provide the first large-scale analysis of the scaling patterns of the cervical spine and its constituting cervical vertebrae. Our findings reveal that the opposite allometric scaling of C1 and C2-C7 accommodate the increase of neck bending moment with body size. The internal organization of the neck skeleton exhibits surprisingly uniformity in the vast majority of mammals. Deviations from this general pattern only occur under extreme loading regimes associated with particular functional and allometric demands. Our results indicate that the main source of variation in the mammalian neck stems from the disparity of overall cervical spine length. The mammalian neck reveals how evolutionary disparity manifests itself in a structure that is otherwise highly restricted by meristic constraints.
\end{abstract}

KEY WORDS: Allometry, mammalian cervical spine, neck evolution, proportions.

Adaptive evolutionary acquisitions involve the generation of variation and subsequent natural selection. Some structures, however, seem to resist evolutionary change and remain in a morphological stasis (e.g., Eldredge and Gould 1972; Smith et al. 1985; Sturmbauer and Meyer 1992; Suno-Uchi et al. 1997; Galis and Metz 2003; Witt et al. 2003; Lecompte et al. 2005; Narita and Kuratani 2005; Hughes 2007; Lavoué et al. 2011). One of the most prominent examples of morphological stasis in vertebrates is the mammalian cervical spine as seven cervical vertebrae are consistently found across almost all mammals (Galis 1999; Narita and Kuratani 2005). According to the paleontological evidence, this consistency dates back more than 200 million years (Jenkins 1971; Crompton and Jenkins 1973). It contrasts with the high vari- ation in the number of neck vertebrae found across other extant and extinct tetrapod lineages (Müller et al. 2010). For example, evolutionary variation in avian neck length occurs locally by the addition of cervical vertebrae (Van Der Leeuw 1991; Van Der Leeuw et al. 2001). In birds, there seem to be no developmental constraints that fix their number (i.e., variation in vertebral number is rarely accompanied by malformation or cancer) (Fox 1912; Effron et al. 1977; Adelman et al. 1988; Barja et al. 1994; Perez-Campo et al. 1998; Galis 1999).

The developmental framework of the mammalian cervical spine has gained considerable attention in the last few decades. Several studies have revealed processes in the prenatal development constraining meristic variability in the neck (Galis 1999; 
Galis and Metz 2003; Galis et al. 2006; Galis and Metz 2007; Buchholtz 2012; Buchholtz et al. 2012; Hirasawa and Kuratani 2013; Buchholtz 2014; Hirasawa et al. 2016). These findings give the rationale for the evolutionary stasis in the number of neck vertebrae across mammals. In some mammalian clades, however, natural selection favored the increase or the decrease in neck length, such as in giraffes and whales, respectively. The requirements associated with these neck length modifications have to be met within the fixed number of cervical vertebrae (Woltering and Duboule 2015). The pattern of vertebral size modification is hence of particular importance, as the general shape of the individual vertebrae $(\mathrm{C} 1-\mathrm{C} 7)$ is quite conserved across mammalian lineages and their body size range (Johnson and O'Higgins 1996; Johnson et al. 1999; Buchholtz and Stepien 2009; Buchholtz et al. 2012; Buchholtz et al. 2014; Arnold et al. 2016). Nevertheless, it is not clear whether scaling of neck length is achieved by uniform modification of the whole cervical spine or by individual vertebra length alteration. Furthermore, it is not clear whether the overall length of the cervical spine and its inner organization are influenced by body size (i.e., subject to allometry).

Although altering body size is a crucial component of mammalian evolutionary diversification, the associated biomechanical implications raise an important evolutionary challenge (Thompson 1917; Huxley 1932). Scaling analyses of vertebral metrics among particular mammalian clades have recently provided crucial insights into the evolutionary variation of the axial skeleton (Viglino et al. 2014; Jones 2015; Jones and Pierce 2016; Randau et al. 2016). It is worth noting, however, that most investigations of cervical variation to date have focused on particular clades with either an aberrant number of vertebrae (i.e., departing from the seven-vertebrae rule, namely sloths and the manatee) (Buchholtz et al. 2007; Buchholtz and Stepien 2009; Hautier et al. 2010; Varela-Lasheras et al. 2011; Endo et al. 2013; Buchholtz et al. 2014) or with an extreme neck length (Lankester 1908; Solounias 1999; Van Schalkwyk et al. 2004; Badlangana et al. 2009; Van Sittert et al. 2010; Mitchell et al. 2013; Danowitz and Solounias 2015; Danowitz et al. 2015; Gunji and Endo 2016). Naturally, these approaches do not encompass the full range of mammalian cervical length and body size. Krüger (1958) compared the anatomy of the cervical vertebrae of most mammalian orders but did not use a quantitative approach. Accordingly, to date no large-scale comparative dataset exists that would permit the inference of general patterns of cervical scaling to body size or to neck length.

The scope of our study is (1) to infer the relationship between cervical spine length and body size across the full range of mammalian sizes; (2) to examine patterns of cervical spine length and individual vertebral length scaling in mammals in general, as well as in several subclades; (3) to assess whether scaling is uniform among individual vertebrae; and (4) to establish a general rule that governs neck design in mammals. We compare the lengths, proportions, and scaling properties of the individual cervical vertebrae as well as the whole cervical spine across a large dataset of mammals. The final goal of our study is to look for similarities in cervical spine construction across mammals. We want to confront our findings with the neck's biomechanical determinants in mammalian evolution. We also aim to discuss them in the context of the fixed number of seven vertebrae found in virtually all mammals.

Mechanical models suggest that the vertebral centra (the body of the vertebra) form the major compressive support structure in the neck region (Slijper 1942; Kummer 1959a,b; Smit 2002). Thus, we focused on the scaling patterns of the vertebral centra. They most directly relate to variation in compressive loadings, which reflects the disparity in body size, head size, and neck length.

\section{Material and Methods DATA ACQUISITION}

Our sample consists of 467 specimens representing 352 species of mammals. All main clades of monotremes, marsupials, and placentals were represented (Fig. 1; for more details, see Table S1). The sample comprises of mammals that employ various foraging strategies (e.g., carnivores, herbivores, omnivores) and locomotor specializations (e.g., terrestrial, fossorial, aquatic, saltatorial, biped, volant). Taxa with an aberrant number of cervical vertebrae (i.e., sloths and manatees) were excluded from the analysis. Taxa in which some of the vertebrae are fused were only included if the borders of subsequent vertebral bodies were clearly recognizable (e.g., in cetaceans and some xenarthrans). The sampled specimens are housed in the collections of the Phyletisches Museum Jena, Senckenberg Forschungsinstitut und Naturkundemuseum Frankfurt, Museum für Naturkunde-Leibniz-Institut für Evolutionsund Biodiversitätsforschung zu Berlin, Staatliche Museum für Naturkunde Stuttgart and Naturkundemuseum Erfurt. CT scans from German zoo animals provided by the Hospital of Small Animal Surgery, University of Gießen, were also included in the dataset (see Table S2 for a complete list of specimens). For species represented by more than one specimen, mean values were used in all subsequent calculations.

Individual cervical vertebra lengths were measured along the ventral side of the vertebral bodies in the sagittal plane (i.e., vertebral centrum length) using a digital caliper (accuracy: $0.01 \mathrm{~mm}$ ). Atlas length was measured as the length of the ventral half of the bony ring (i.e., its thickness in a craniocaudal direction) excluding the caudally directed ventral tubercle. The odontoid process was excluded from the measurement of axis length, as it does not contribute to cervical spine length due to its position within the bony ring of the atlas when articulated. For specimens with 


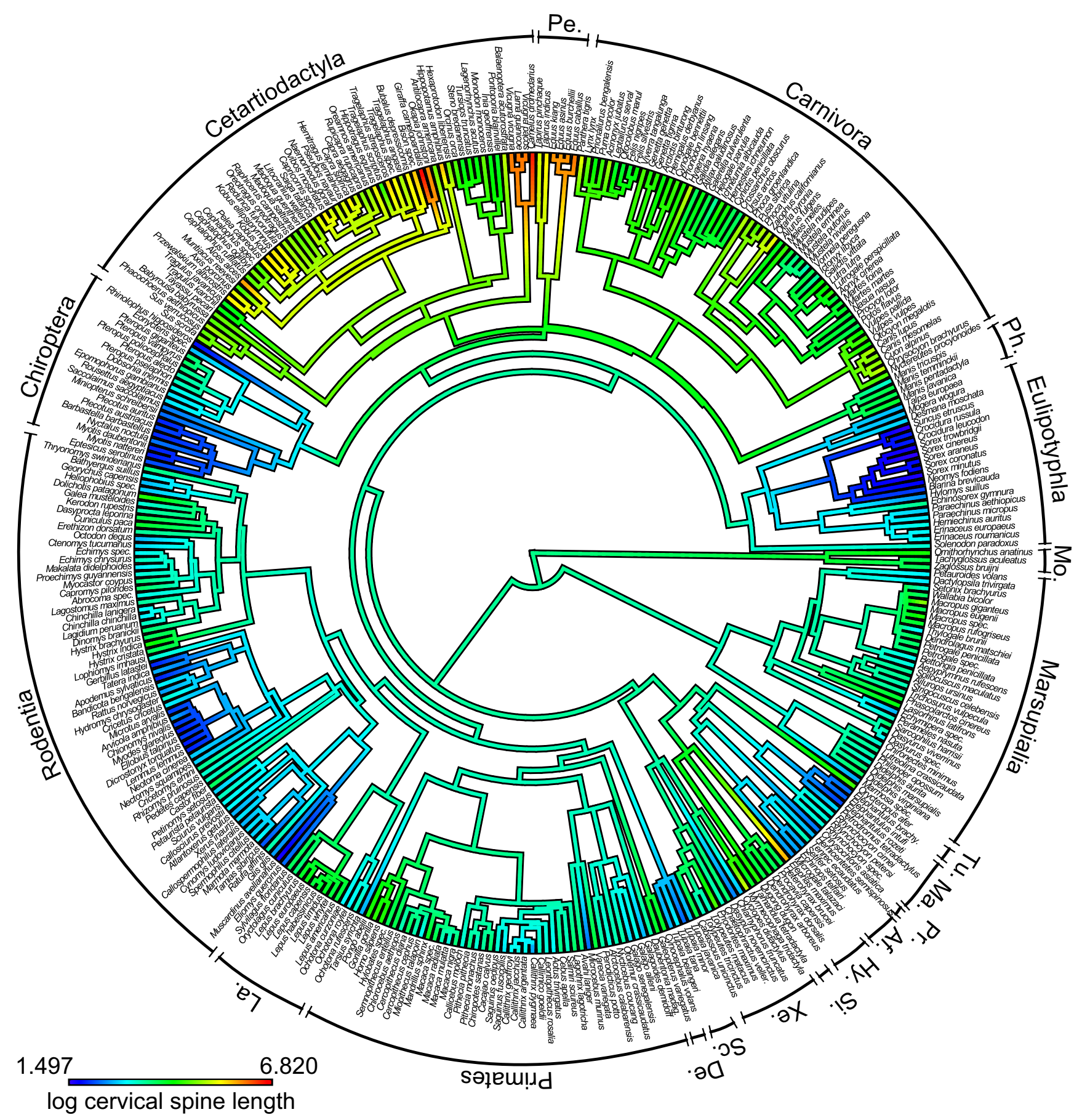

Figure 1. Timetree of the 352 mammalian species from 272 genera sampled for this study. The cervical spine length (log-transformed) is mapped on the branches. Af., Afrosoricida; De., Dermoptera; Hy., Hyracoidea; La., Lagomorpha; Ma., Macroscelidea; Mo., Monotremata; Pe., Perissodactyla; Ph., Pholidota; Pr., Proboscidea; Sc., Scandentia; Si., Sirenia; Tu., Tubulidentata; Xe., Xenarthra.

vertebrae smaller than $3 \mathrm{~mm}$, cervical spines were scanned at a voxel size of $37 \mu \mathrm{m}$ at the Institute of Diagnostic and Interventional Radiology, Jena University Hospital. Vertebral lengths were measured subsequently from extracted surfaces in the software Amira 5.4.2 (Visage Imaging, Richmond, Australia). Total cervical spine length was calculated as the sum of the seven vertebrae and did not include any estimates of the size of the intervertebral discs or intercentrum cartilage (see Badlangana et al. 2009). Vertebral proportions were calculated as the percentage of the total cervical spine length represented by each vertebra.

Body mass was used as a body size proxy. For the majority of collection specimens, the body mass was not available. The 
majority of information was hence taken from the AnAge database (Human Aging Genomic Resources, University of Liverpool, Liverpool, United Kingdom) (Tacutu et al. 2012) (accessed at: http://genomics. senescence.info/species/) and completed from the literature (Nowak 1999; Kingdon 2015). Additionally, we also used tibial length as an alternative body size proxy (see Schmidt and Fischer 2009), which is individually associated with the sampled specimens. See Table S3 for the original data.

\section{STATISTICS}

The overall cervical spine length and individual vertebral lengths were investigated to test whether allometric scaling is a significant source of their variation. Accordingly, they were regressed against a body size proxy to assess their relationship to body size for all mammals. All regressions were additionally performed for Carnivora, Cetartiodactyla, Marsupialia, Primates, and Rodentia ( $>70 \%$ of the total sample) to compare deviations from the general mammalian pattern. These regressions were also performed on (super)familial taxonomic levels (Bovidae, Caviomorpha, Cercopithecidae, Felidae, Leporidae, Macropodidae + Potoroidae, Muroidea, Mustelidae, Platyrrhini, Pteropodidae, Sciuromorpha, Soricidae) in which at least nine species were available.

R 3.3.1 (R Core Team 2016) was used for all calculations with the following significance levels of $P$ values: $* P<0.05$, $* * P<0.01$, and $* * * P<0.001$ ( $\mathrm{R}$ script provided in the supplement). All data were right-skewed and highly kurtotic (skewness $>>0 * * *$, D'Agostino test; (D'Agostino 1970); kurtosis $>>$ 3***, Anscombe-Glynn test (Anscombe and Glynn 1983); "moments" package; (Komsta and Novomestky 2014). To account for this, they were log-transformed.

Phylogenetically informed methods were used to take the phylogenetic relationships of the sample taxa into account. The Timetree of life (TOL; Hedges et al. 2015) resolved at the species level (accessed at http://timetreebeta.igem.temple.edu/) was modified according to our sampling with Mesquite 3.10 (Maddison and Maddison 2011). See additional details on the timetree construction in the supplements; the resulting timetree is given as a nexus file. Following the recommendation of Revell (2010), we used the generalized least squares function of the "nlme" 3.1128 package (Pinheiro et al. 2008), with Pagel's $\lambda$ (Pagel 1999) correlation structure ("ape" 3.5 package (Paradis et al. 2004). This method simultaneously estimates the regression model and phylogenetic signal (using Pagel's $\lambda$, which outperforms other commonly used indices (Münkemüller et al. 2012). For some of the subclades with small sample sizes, the phylogenetic signal was so small that the regression model was not successfully estimated. In these cases, we used traditional generalized least-square regressions. A slope test was used to compare the scaling of each relationship to the coefficient denoting isometry (with body mass:

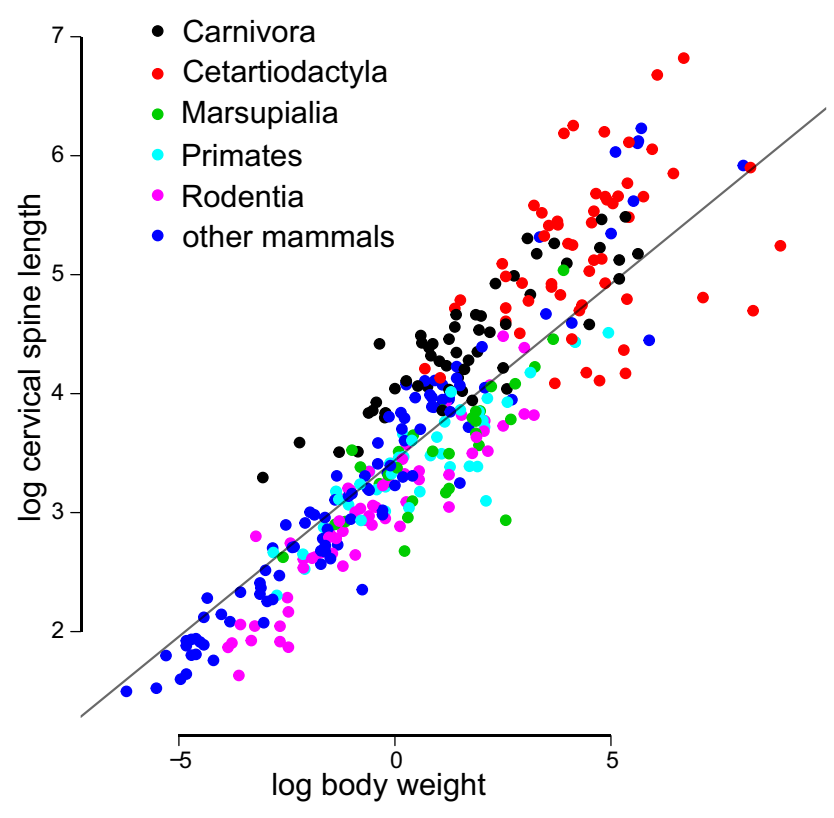

Figure 2. Regression of log cervical spine length against log body weight for 352 mammalian species. Colors code for the major mammalian clades. The gray line represents the phylogenetic informed regression for all mammals.

1/3; with tibial length: 1 ), using the Student's $t$ distribution ("pt" function). A correction for multiple testing (Holm-Bonferroni method, "p.adjust" function) was finally applied to the slope test $P$ values.

We also used a phylogenetically informed multivariate approach to investigate the relationships among the vertebral lengths, the cervical spine length, and body weight, thanks to the "phyl.pca" function of the "phytools" 0.5-38 package (Revell 2012). Additionally, patterns of variation according to cervical organization were further explored and visualized using a ternary plot ("ggtern" 2.2.0 package; (Hamilton 2016) and 95\% confidence lines (using Mahalanobis distances) on groups of covarying vertebrae (inferred from the PCA, see below).

\section{Results}

\section{SCALING OF OVERALL CERVICAL SPINE LENGTH}

The overall cervical spine length scales with negative allometry against body weight (Figs. 2 and 3; Table S4) across all mammals (slope $=0.3 * *$ ) as well as in the individual analyses of carnivorans, cetartiodactyls, marsupials, primates, and rodents (slope $=0.25-0.28$; the deviation from isometry, however, is not significant in the latter three). Thus, the cervical spine shortens relatively as body size increases. This result reveals the importance of taking phylogeny into account, as a traditional linear regression finds positive allometry in the same data. The residuals from the regression (scatter around the regression line) are 


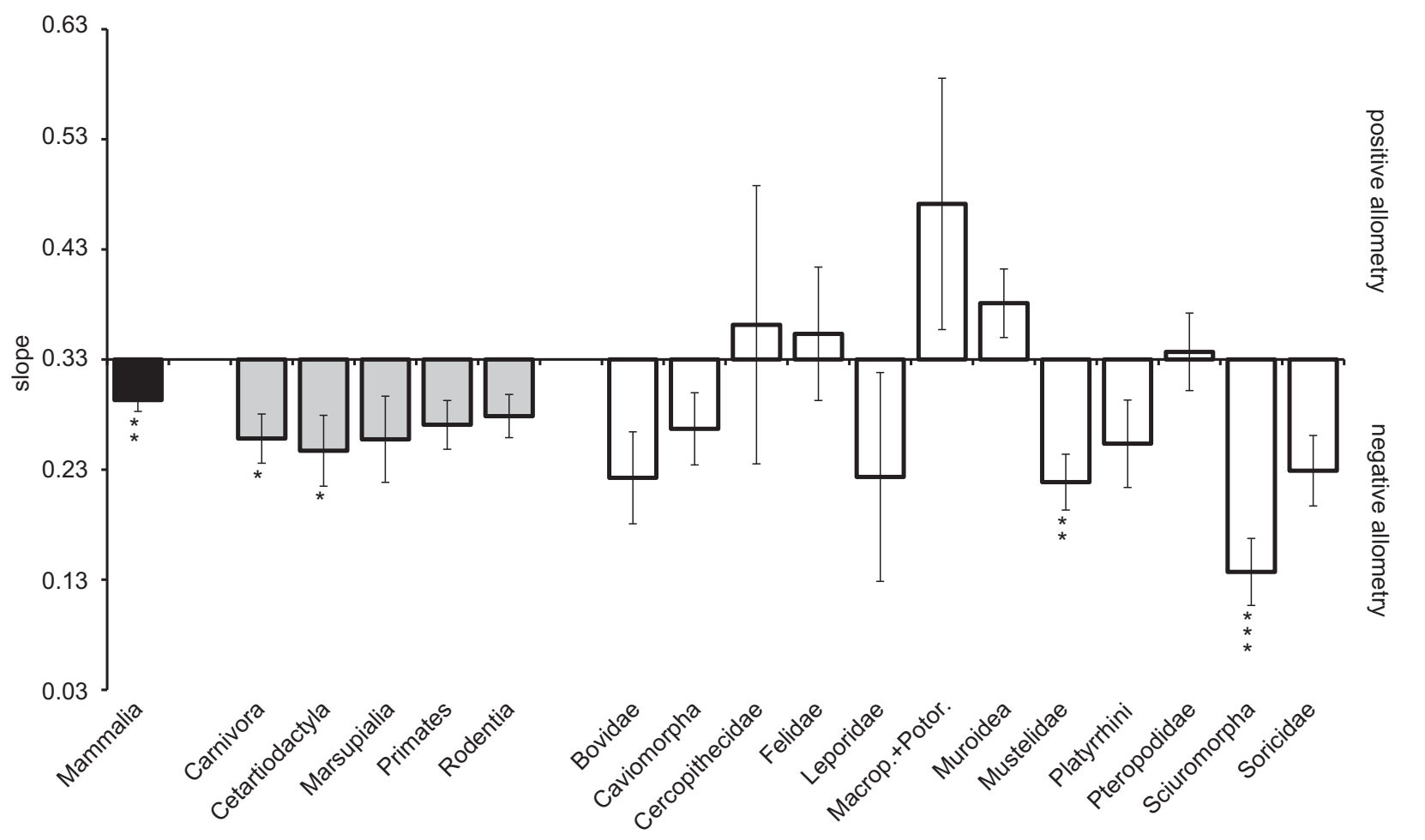

Figure 3. Comparison of the slopes for the regressions of log cervical spine length against log body weight for mammals in general (dark gray), the major mammalian clades (light gray), and on the (super)familial level (white). The error bars represent the SE of the slopes. Asterisks indicate the significance of slope tests for allometry (i.e., significant different from isometry, corrected for multiple testing, significance levels: $* P<0.05 ; * * P<0.01 ; * * * P<0.001$ ).

large, specifically in carnivorans, cetartiodactyls, and marsupials, and especially for large-sized species (Fig. 2). Similar results are also found when looking at the (super)familial taxonomic level, however, with much more variability (Fig. 3). At this level, the cervical spine also scales either isometrically or with negative allometry depending on the groups. The macropodid-potoroid clade (and to a lesser extent the muroids) is the only exception as it scales with positive allometry. Regressions on tibial length (the alternative body size proxy) revealed very similar results (Table S5).

\section{SCALING OF THE INDIVIDUAL CERVICAL VERTEBRAE}

In mammals in general, all individual cervical vertebrae apart from $\mathrm{C} 1$ scale with negative allometry and thus relatively shorten with increasing body size (Fig. 4; Table S6). C1, in contrast, scales with positive allometry. These slope differences result in a cervical length internal organization (i.e., the set of individual vertebra proportions) that changes with varying body size. Similar patterns are again found in carnivorans, cetartiodactyls, marsupials, primates, and rodents, particularly for C2-C7 (Fig. 4 and Table S5). In marsupials, however, $\mathrm{C} 1$ scales with strong negative allometry.
Significance at the (super)familial level is low due to reduced sample sizes. However, in most cases, C2-C7 describe patterns similar to those of the larger clades (Table S6). C1 scales with positive allometry in taxa, which include a wide range of body sizes (e.g., bovids, felids). In contrast, it scales with negative allometry or isometry in taxa in which differences in body size are low (e.g., sciuromorphs, soricids). Regressions on tibial length revealed very similar results (Table S5).

\section{PHYLOGENETIC PRINCIPLE COMPONENT ANALYSIS AND VERTEBRAL COVARIATION}

In addition to the bivariate regression analyses, we also conducted a phylogenetic PCA to reveal more detailed patterns of vertebral covariation (Fig. 5). PC1 and PC2 together account for more than $96 \%$ of total variation (Table S7). PC1 loadings are high for all parameters (Table S7). PC1 therefore does not elucidate any further conclusions regarding particular vertebral patterns. However, when examining PC1 against PC2, the loading vectors form three distinct groups. The $\mathrm{C} 1$ vector is widely separated from the other vertebrae vectors and plots close to the body weight vector. The second group is composed of C2, C7 (i.e., the vertebrae making transition with the rest of the spine), and the whole cervical spine length vectors. The third group includes the 


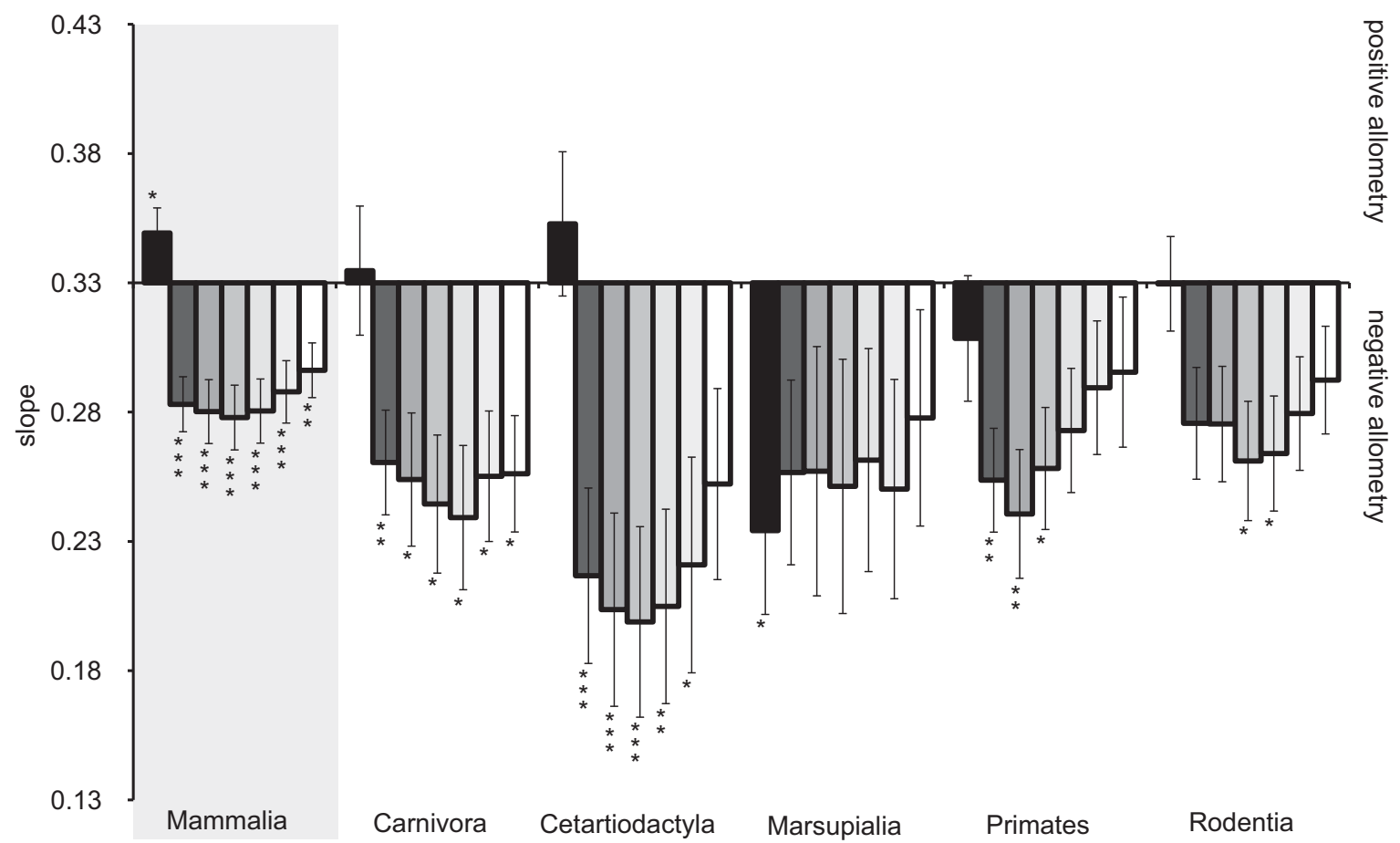

Figure 4. Comparison of the slopes for the regressions of log vertebral lengths against log body weight for C1 (dark gray) to C7 (white) in mammals in general and the major mammalian clades. The error bars represent the SE of the slopes. Asterisks indicate the significance of slope tests for allometry (i.e., significant different from isometry, corrected for multiple testing, significance levels: $* P<0.05$; $* * P<0.01 ; * * * P<0.001)$.

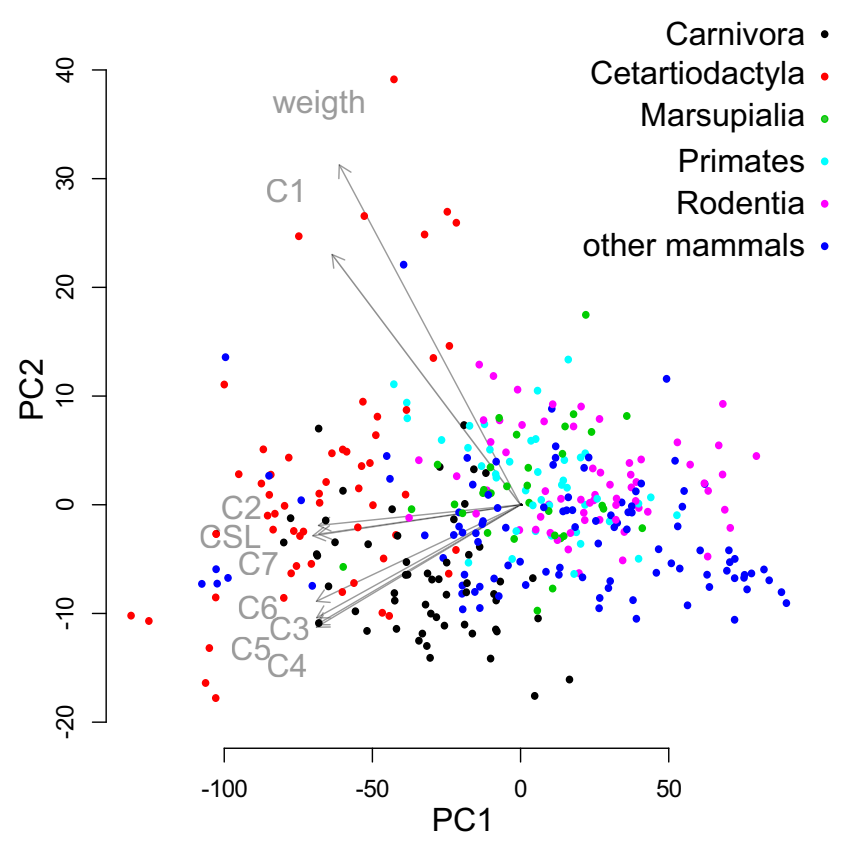

Figure 5. Results of the phylogenetic principle component analysis (phyIPCA) on body weight, cervical spine length (CSL), and vertebral lengths (C1-C7). PC1 and PC2 together account for more than $96 \%$ of total variation. Colors code for the major mammalian clades. The loading vectors (gray arrows) form three distinct groups: $\mathrm{C} 1+$ body weight; $\mathrm{C2}+\mathrm{C} 7+\mathrm{CSL}$; $\mathrm{C} 3-\mathrm{C} 6$. vectors of C3-C6 (i.e., the mid-cervical vertebrae), which strongly covary.

\section{VERTEBRAL PROPORTIONS}

The proportions of the three classes of cervical vertebrae suggested by the loading vectors of the phylogenetic PCA (i.e., $\mathrm{C} 1, \mathrm{C} 2+7$, and $\mathrm{C} 3-\mathrm{C} 6)$ are visualized using a ternary graph (Fig. 6). Most species are densely clustered in a small portion of the ternary space (framed by the triangular $95 \%$ confidence line). This indicates that the three-class pattern of cervical organization is quite uniform across most mammals. However, there are three main deviations from this pattern that can be linked to particular functional demands (Figs. 6 and 7). First, long-necked mammals including the giraffe (Giraffa camelopardalis), camelids, and small-horned/nonhorned antilopin bovids cluster on the bottom right. They possess relatively long C3-C6 but short $\mathrm{C} 1$ and $\mathrm{C} 2+7$ (especially C7; Fig. 7). Second, several (but not all) fossorial species cluster on the top. These species have relatively long $\mathrm{C} 2+7$ but short $\mathrm{C} 1$ and C3-C6 (e.g., the marmot [Marmota marmota], the cape golden mole [Chrysochloris asiatica], and several dasypodid armadillos). And third, located in the bottom left are the large-headed and/or fully aquatic species possessing a massive $\mathrm{C} 1$ but relatively short C3-C6 (cetaceans, the elephant [Elephas maximus], the dugong [Dugong dugon], and large bovids). 


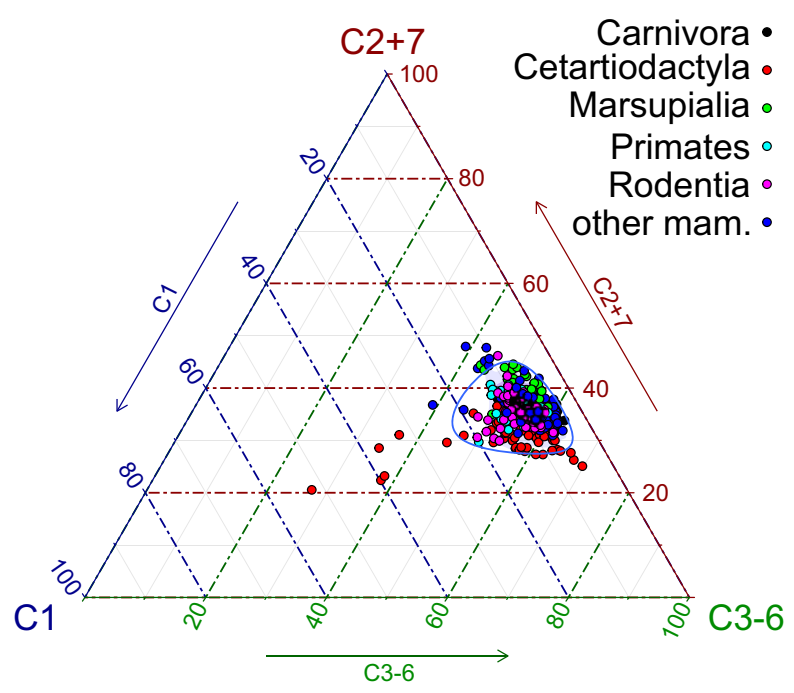

Figure 6. Ternary plot visualizing the proportions of the three vertebral classes (C1; C2 + C7; C3-C6) for the necks of 352 mammalian species. Colors code for the major mammalian clades. The majority of mammals densely clusters in only a small fracture of the full ternary space (framed by the blue $95 \%$ confidence line) suggesting an only limited variation in vertebral proportions. Only few species deviate from this pattern in three directions (shaded in gray; see Fig. 7).

The ternary plot also reveals the diversity of cervical spine traits among cetartiodactyls (red dots in Fig. 6). They occupy a large but continuous range in the ternary space. They range from large-headed but short-necked species (cetaceans, hippopotamids, large bovids) at the bottom right to medium-length necked species in the center (suids, tayassuids smaller sized pecorans) up to slender-headed but long-necked species on the bottom right (cervids, antilopines, giraffids, camelids).

\section{Discussion}

\section{BODY SIZE AND NECK LENGTH IN MAMMALS}

The general mammalian trend for the overall cervical spine length is to decrease with increasing body size. This was expected because the weight of the head increases (e.g., Cardini and Polly 2013; Cardini et al. 2015) with a power of three, whereas the stress-resisting cross-sectional area of the neck only increases with a power of two (Preuschoft and Klein 2013). To reduce neck bending moment, a relative decrease in the distance between the head's center of mass and its center of rotation (i.e., the cervico-thoracic junction) is required. This results in the negative allometry observed in the neck length scaling. This interspecific structural allometry (changes in bone structure with increasing body size) (McMahon 1973; McMahon 1975; Alexander et al. 1979) provides an important solution to maintaining acceptable safety factors in the neck skeleton (particularly in large mammals).
A stouter cervical spine can withstand greater peak stresses (Alexander et al. 1979; Jones 2015). Negative allometry in the length of the cervical spine matches the results from the lumbar spine (e.g., Halpert et al. 1987; Majoral et al. 1997; Jones 2015). This suggests common body size constraints on the axial regions due to the combined function of load bearing and motion. In the mammalian clades in which cervical spine length scales isometrically (predominantly those of lower body sizes), postural allometry (changes in posture with increasing body size) (Alexander 1981; Bertram and Biewener 1990; Christiansen 1999; Biewener 2000) might also play an important role in reducing peak stresses and neck bending moment. For instance, small quadrupedal mammals raise their neck in a nearly vertical position and thereby reduce the lever arm of the head weight (especially during resting) (Vidal et al. 1986; Graf et al. 1995b).

The scatter around the regression line (Fig. 2) shows that cervical spine scaling is not uniform across mammalian lineages and that a good approximation of actual neck length cannot be extrapolated from body size in all clades (particularly for large-sized species and in carnivorans, cetartiodactyles, and marsupials). This variability is most likely due to the diversity of functional demands on the neck, as it is the main head actuator during daily activities (grooming, mating, drinking, exploration/sensing, and different modes of locomotion, posture, and foraging) (Heidweiller et al. 1992).

Departing from the uncovered overall allometric scaling, we observed that the cervical spine has been elongated beyond biomechanical predictions in some lineages. This is permitted by the extension of passive bracing elements. Camelids, giraffids, equids, and some antilopin bovids are characterized by a well-developed nuchal ligament permitting the stabilization of a long neck (Mobarak and Fouad 1977; Dimery et al. 1985; Bianchi 1988; Endo et al. 1997; Gellman and Bertram 2002; Preuschoft and Klein 2013). It is often associated with a coelongation of the limbs (Simmons and Altwegg 2010), which increases cursoriality while allowing the head to reach the ground. In contrast to other clades, the kangaroo sensu lato (macropodid-potoroid clade) show a strong positive allometry of the cervical spine. This is most likely related to their upright posture and bipedal-saltatorial locomotion (e.g., Grand 1990; Bennett and Taylor 1995; Chen et al. 2005). As the head is balanced on top of a vertical cervical column, negative allometry to reduce neck bending moment is not required. It is noteworthy that the relatively long neck of the kangaroo is regarded as providing increased head mobility to compensate for the increasing rigidity of the rest of the axial skeleton with increasing body size (Chen et al. 2005).

\section{INTERNAL ORGANIZATION OF THE CERVICAL SPINE}

The atlas (C1) is characterized by a unique scaling pattern, being the only vertebra that scales with positive allometry across 


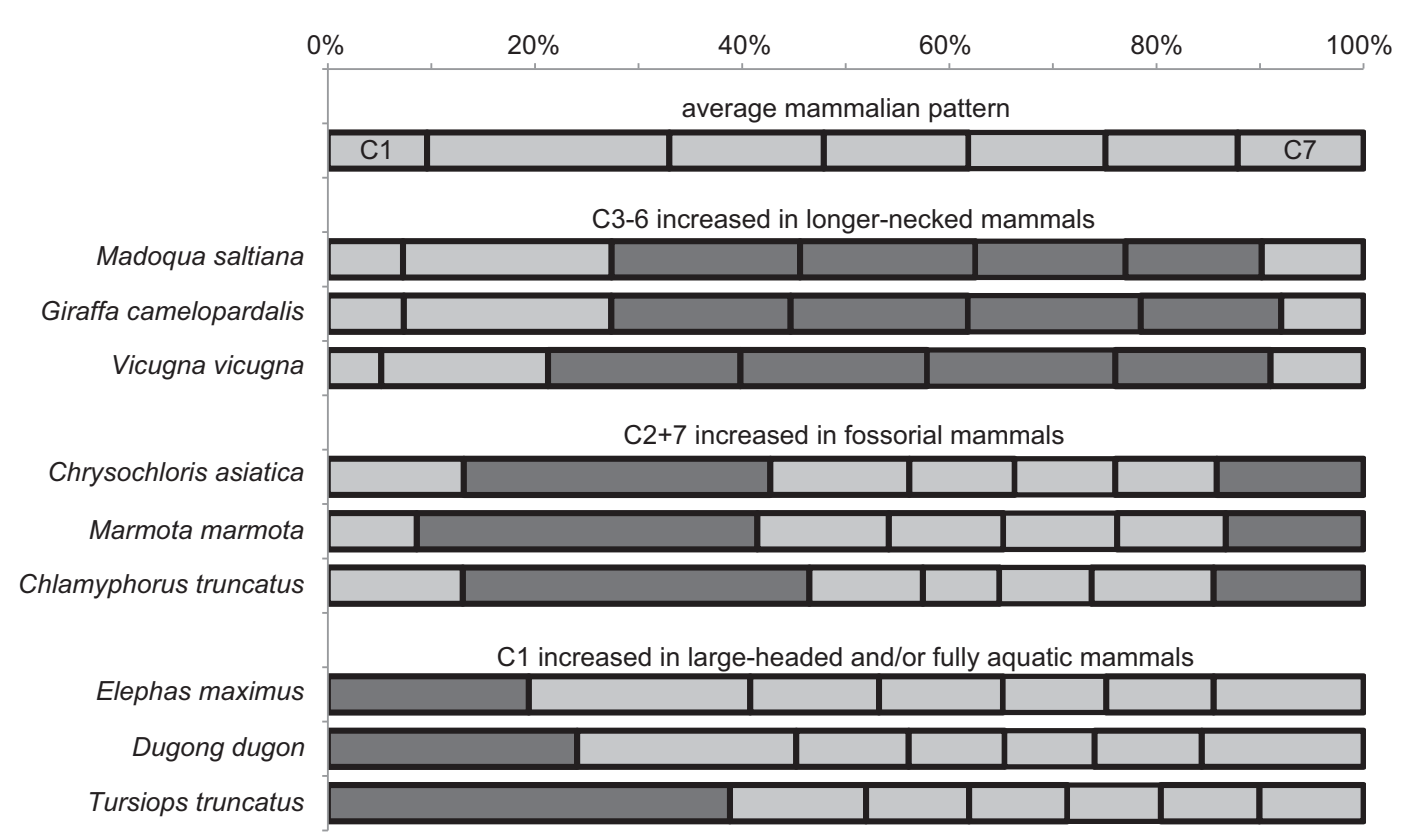

Figure 7. Average internal organization of the mammalian neck compared to species representing the extremes of vertebral variation under altered loading regimes. The bars represent the vertebral proportions of C1-C7 (from left to right). Dark gray areas indicate those vertebra whose proportion are increased.

all mammals. C2-C7 scale with negative allometry and are thus responsible for the overall reduction of the cervical spine length with increasing size. Among most mammals, the cervical internal organization is quite uniform and $\mathrm{C} 1$ accounts for most of the observed variation. The allometric pattern of $\mathrm{C} 1$ and the variability of its relative length reflect mammalian skull diversity in terms of size, weight, and posture (e.g., Manfreda et al. 2006). The atlas transfers the load of the head to the rest of the cervical spine. It provides not only the articular facets for the occipital condyles (which also increase with body size), but also the area of origin of the important monoarticular suboccipital muscles. Thus, despite the need for reducing neck length with increasing body size, the increase in $\mathrm{C} 1$ length maintains the stability of the craniocervical junction with increasing head size. Despite the close functional and developmental integration of C1 and C2 (Evans 1939; Jenkins 1969), their scaling within the cervical spine is completely different.

The phylogenetically informed PCA revealed important patterns in the construction of the cervical spine. Three vertebral classes were recognized: C1, C2 + C7, and C3-C6 (Fig. 5). They, respectively, correspond to three functional regimes: the accommodation of the head, the transition with the rest of the spine, and the inner bulk of the neck. When considering these three classes, it is most noteworthy that the internal organization of the cervical spine is found as particularly uniform across mammals (Fig. 6). Both the scaling patterns of the individual vertebrae and their complex interrelationship represent a general principle that governs neck design in mammals.
This pattern can nevertheless be drastically changed in species with extreme loading regimes. Camelids, giraffids, and some antilopin bovids, which include the species with the longest necks in our dataset, all have very similar proportions, including very long C3-C6 (65-70\%) but short $\mathrm{C} 1$ and $\mathrm{C} 2+7$, especially C7 (Fig. 7). In these species, skulls are long but relatively slender, involving a reduced load bearing function for $\mathrm{C} 1$. Their general neck posture has to become steeper to bring the center of mass of the head closer to the center of rotation of the neck, that is, the cervicothoracic junction (thus reducing neck bending moment). This is enabled by a shortening of C7 as shorter vertebrae decrease the radius of curvature of the concerned articulation (Preuschoft and Klein 2013). Similar cervical traits are also found in extinct long-necked mammals, such as the "South American native ungulate" Macrauchenia (Litopterna, Macraucheniidae) (Huxley 1861; Cope 1891) or the giant rhinoceros Paraceratherium (Perissodactyla, Hyracodontidae) (Forster-Cooper 1911; Osborn and Berkey 1923; Granger and Gregory 1936). In contrast, some fossorial species have relatively long and massive $\mathrm{C} 2$, resulting in $\mathrm{C} 1$ and $\mathrm{C} 2$ together representing more than $40 \%$ of the total cervical spine length (Fig. 7). As a result, the cranial region of the neck is stabilized, and the head fulcrum is enhanced but overall neck mobility is reduced (Bogduk and Mercer 2000). This is further enhanced in some lineages with the fusion of $\mathrm{C} 2$ with midcervical vertebrae (Gupta 1966; VanBuren and Evans 2017). Similarly, large-headed and/or fully aquatic species (elephants, large bovids, cetaceans, and dugongs) are also characterized by relative long vertebrae in the cranial most region of their cervical 
spine (Fig. 7). C1 length is strongly increased to transfer the load of the massive head or to resist water pressure. This third group confirms the allometric pattern of $\mathrm{C} 1$ recovered by the bivariate analyses. In some cetaceans, this is enhanced by cervical coossification, which prevents uncontrolled head movements caused by water pressure during swimming (Slijper and Harrison 1979; Buchholtz 2001; VanBuren and Evans 2017). Head motion relative to the axial skeleton is furthermore restricted by powerful suboccipital muscles and shortening of C2-C7 (Schulte and Smith 1918; Howell 1930).

These examples reveal that variations in cervical construction are associated with extreme loading conditions. Nevertheless, cervical proportions describe a trilateral continuum of variation across mammals (Fig. 6). The deviations from the general pattern represent the three extrema of the variation. Bivariate relationships between the individual vertebrae and body size are, however, strongly impacted by these species with extreme neck loading regimes. Much of the variation in cervical spine length, as well as in the individual vertebral lengths and proportions, is found in cetartiodactyls, due to the high degree of differentiation of neck morphology and function found in this lineage (neck length, skull and appendages morphology, feeding and locomotor habits) (see Vislobokova 2013).

\section{BIOMECHANICAL DETERMINANTS OF CERVICAL ORGANIZATION}

The general construction and internal organization of the cervical spine is strongly based on the divergent scaling of $\mathrm{C} 1$ compared to $\mathrm{C} 2-\mathrm{C} 7$, which is shared by almost all mammals. However, the fact that the muskox (Ovibos moschatus; proportions of the individual vertebrae $(\%)$ on the whole cervical spine $=17: 21: 14: 13: 13: 11: 11$ ) has almost the same cervical vertebra proportions as the garden dormouse (Eliomys quercinus; 16:21:14:13:12:11:13) shows that there are no universal rules relating the cervical spine construction to body size, habitat, and locomotion. The low variability of cervical internal organization (under nonextreme loading regimes) raises questions about the role of individual vertebra proportions in neck functions. From a biomechanical point of view, the cervical spine is uniformly constructed across mammals. It constitutes a loaded beam that is supported at one end only (i.e., a cantilever) (Kummer 1959a,b). The weight of the head permanently induces stresses (tension and compression) on the neck. As a result, the head tends to collapse downward in an unbraced condition (Martin et al. 1998). Unlike in birds and long-necked sauropods, head/neck support in mammals is complicated by the efficient masticatory apparatus (notably involving the important weight of the masticatory muscles). To counteract cervical stresses, passive (nuchal and spinal ligaments) and active (dorsal neck muscles) elements stretch from the anterior region of the trunk to the head and the cervical ver- tebrae. As the nuchal elements completely compensate the neck bending moment to allow the head and neck to maintain their posture, the cervical vertebrae are under purely axial load (Kummer 1959a,b). This general construction limits variation in the length of vertebral centra, the major load bearing structures (Slijper 1942; Kummer 1959a,b; Smit 2002). Consequently, a similar internal organization of the neck is found in most mammals, even if they have quite different neck lengths and/or different locomotor and foraging modes. Our findings confirm the conclusions of Badlangana et al. (2009) that variation in neck lengths in ungulates does not necessarily involve variation in cervical internal organization. However, this principle is now extended to mammals in general. Only under extreme loading regimes of the neck (e.g., massive heads, extremely long necks, fully aquatic and fossorial lifestyle), internal organization is modified to accompany exceptional mechanical requirements. Cervical proportions seem to be adjusted to high craniocervical mobility (Graf et al. 1995a,b), but also to reduce kinematic redundancy (Bizzi et al. 1976; Vidal et al. 1986; Peterson et al. 1989; Keshner 1990; Pellionisz et al. 1991; Graf et al. 1995a; Van Den Berg 2000) within the limits of biomechanical determinants. The surprisingly consistent internal organization of the mammalian cervical spine therefore provides the basis of high functional diversity, despite a relatively low and invariable number of mobile elements.

\section{THE EVOLUTION OF CERVICAL SPINE LENGTH IN MAMMALS}

The seven cervical vertebrae rule of mammals is most likely an evolutionary by-product (Gould and Lewontin 1979) of key innovations in mammalian metabolic and locomotor performance (enhanced metabolism, muscularized diaphragm, thoracolumbar differentiation) (Galis 1999; Galis and Metz 2003; Galis et al. 2006; Varela-Lasheras et al. 2011; Buchholtz 2012; Buchholtz et al. 2012; Hirasawa and Kuratani 2013; Buchholtz 2014; Galis et al. 2014; Hirasawa et al. 2016). Thus, the fixed number is unrelated to the craniocervical function itself. Strong negative selection due to the pleiotropic effects of Hox genes in the early development and the strong developmental integration between the cervical region and other body parts (cervical origin of the precursor cells for forelimb and diaphragm muscles) in late development place a strong constraint on the cervical count (see references above). Accordingly, variation corresponding to functional/biomechanical demands are postponed to the late (postnatal) development during vertebral growth (i.e., during the formation of size of the cervical spine as a whole as well as that of the individual vertebrae) (see Bergmann et al. 2006; Van Sittert et al. 2010).

In contrast to its highly determined internal organization, the disparity of overall cervical spine length is the main source of variation of the mammalian neck. We assume that variation in neck length is generally limited by body size due to its biomechanical 
requirements as a cantilever (as also argued by Kummer 1959a,b). However, the various scaling patterns permit the adjustment of neck length to the demands of head movement and posture (e.g., grooming, mating, drinking, foraging, locomotion, and posture; see Heidweiller et al. 1992) within this limited possible variation. In some species and lineages, natural selection even favored an extreme increase or decrease in neck length. Although maximum neck length in mammals is still not comparable to that of most sauropods (Taylor and Wedel 2013), this mechanism resulted in the extraordinary large range of cervical spine length acquired during mammalian evolutionary diversification (220-fold increase between the Etruscan shrew and the giraffe in our dataset), despite a fixed number of seven vertebrae. Alteration in vertebral count (Buchholtz and Stepien 2009; Hautier et al. 2010; Varela-Lasheras et al. 2011; Buchholtz et al. 2014) actually represents rare and phylogenetically isolated evolutionary events. Alteration of the whole neck length seems to be an important source of cervical variation in mammals, as already suggested by Gans (1992). Due to the combination of large variation in overall length, but limited variation in internal organization, the cervical spine can act as a form-function complex (Bock and Von Wahlert 1965) across the various neck lengths that arose during mammalian evolutionary diversification.

\section{Conclusion}

Neck length modification has been crucial in mammalian body size evolution. The developmentally fixed number of cervical vertebrae, however, limits evolutionary modifications in neck length in mammals when compared to birds or sauropods (Van Der Leeuw 1991; Galis 1999). Here, we revealed the patterns of cervical scaling, which nonetheless permits a great disparity of neck length in mammals. Opposite allometric scalings of $\mathrm{C} 1$ and $\mathrm{C} 2-$ C7 accommodate the increase of neck bending moment with body size. A three-class internal organization of the neck skeleton is found with surprisingly uniformity in the vast majority of mammals. Deviations from this general pattern only occur under extreme loading regimes, associated with particular functional and allometric demands. Our results indicate that the main source of variation in the mammalian neck dwells in the disparity of overall cervical spine length. This allows for adaptive modifications to the various demands associated with different head movements and postures (grooming, mating, locomotion, posture, and foraging). The mammalian neck reveals how evolutionary disparity manifests itself in a structure that is otherwise highly restricted by meristic constraints.

\section{AUTHOR CONTRIBUTIONS}

PA designed the study, collected all data, and drafted the manuscript. PA and EA conducted all analyses. PA, EA, and MSF interpreted the data and reviewed the manuscript. The authors declare they have no conflicts of interest.

\section{ACKNOWLEDGMENTS}

We thank I. Hilger for the access to the CT facilities and Y. Ozegowski for her assistance during the recordings (Jena University Hospital). We also thank M. Schmidt (University of Jena), H. Witte (University of Ilmenau), and S. Perry (Bonn University) for their comments on study design and data interpretation, M. Schmidt (Gießen University) for the provision of additional CT scans, F. Mayer and C. Funk (Museum für Naturkunde Berlin), I. Ruf (Senckenberg Naturkundemuseum Frankfurt), S. Merker (Staatliches Museum für Naturkunde Stuttgart), and U. Scheidt (Naturkundemuseum Erfurt) for the access to the collections under their care, and M. Lui for language improvement. We are grateful to M. Zelditch, K. Jones, and one anonymous reviewer for their important suggestions and input on a former version of our manuscript.

\section{LITERATURE CITED}

Adelman, R., R. L. Saul, and B. N. Ames. 1988. Oxidative damage to DNA: relation to species metabolic rate and life span. Proc. Natl. Acad. Sci. 85:2706-2708.

Alexander, R., A. Jayes, G. Maloiy, and E. Wathuta. 1979. Allometry of the limb bones of mammals from shrews (Sorex) to elephant (Loxodonta). J. Zool. 189:305-314.

Alexander, R. M. 1981. Factors of safety in the structure of animals. Sci. Prog. 67:109-130.

Anscombe, F. J., and W. J. Glynn. 1983. Distribution of the kurtosis statistic b2 for normal samples. Biometrika 70:227-234.

Arnold, P., F. Forterre, J. Lang, and M. S. Fischer. 2016. Morphological disparity, conservatism, and integration in the canine lower cervical spine: insights into mammalian neck function and regionalization. Mamm. Biol. 81:153-162.

Badlangana, N., J. W. Adams, and P. R. Manger. 2009. The giraffe (Giraffa camelopardalis) cervical vertebral column: a heuristic example in understanding evolutionary processes? Zool. J. Linn. Soc. 155:736757.

Barja, G., S. Cadenas, C. Rojas, R. Perez-Campo, and M. Lopez-Torres. 1994. Low mitochondrial free radical production per unit $\mathrm{O} 2$ consumption can explain the simultaneous presence of high longevity and high aerobic metabolic rate in birds. Free Radic. Res. 21:317-327.

Bennett, M., and G. Taylor. 1995. Scaling of elastic strain energy in kangaroos and the benefits of being big. Nature 378:56-59.

Bergmann, P. J., A. D. Melin, and A. P. Russell. 2006. Differential segmental growth of the vertebral column of the rat (Rattus norvegicus). Zoology 109:54-65.

Bertram, J., and A. A. Biewener. 1990. Differential scaling of the long bones in terrestrial carnivora and other mammals. J. Morphol. 204:157169.

Bianchi, M. 1988. The thickness, shape and arrangement of elastic fibres within the nuchal ligament from various animal species. Anat. Anz. 169:53-66.

Biewener, A. A. 2000. Scaling of terrestrial support: differing solutions to mechanical constraints of size. Pp. 51-66 in J. Brown, and G. West, eds. Scaling in biology. Oxford Univ. Press, Oxford, UK.

Bizzi, E., A. Polit, and P. Morasso. 1976. Mechanisms underlying achievement of final head position. J. Neurophysiol. 39:435-444.

Bock, W. J., and G. Von Wahlert. 1965. Adaptation and the form-function complex. Evolution 19:269-299.

Bogduk, N., and S. Mercer. 2000. Biomechanics of the cervical spine. I: normal kinematics. Clin. Biomechan. 15:633-648. 
Buchholtz, E. A. 2001. Vertebral osteology and swimming style in living and fossil whales (Order: Cetacea). J. Zool. 253:175-190.

-2012. Flexibility and constraint: patterning the axial skeleton in mammals. Pp. 230-256 in R. Asher, and J. Müller, eds. From clone to bone: the synergy of morphological and molecular tools in palaeobiology. Cambridge Univ. Press, Cambridge, UK.

. 2014. Crossing the frontier: a hypothesis for the origins of meristic constraint in mammalian axial patterning. Zoology 117:64-69.

Buchholtz, E. A., and C. C. Stepien. 2009. Anatomical transformation in mammals: developmental origin of aberrant cervical anatomy in tree sloths. Evol. Dev. 11:69-79.

Buchholtz, E. A., A. C. Booth, and K. E. Webbink. 2007. Vertebral anatomy in the Florida manatee, Trichechus manatus latirostris: a developmental and evolutionary analysis. Anat. Rec. 290:624-637.

Buchholtz, E. A., H. G. Bailin, S. A. Laves, J. T. Yang, M. Y. Chan, and L. E. Drozd. 2012. Fixed cervical count and the origin of the mammalian diaphragm. Evol. Dev. 14:399-411.

Buchholtz, E. A., K. L. Wayrynen, and I. W. Lin. 2014. Breaking constraint: axial patterning in Trichechus (Mammalia: Sirenia). Evol. Dev. 16:382393.

Cardini, A., and P. D. Polly. 2013. Larger mammals have longer faces because of size-related constraints on skull form. Nat. Commun. 4:24582464.

Cardini, A., D. Polly, R. Dawson, and N. Milne. 2015. Why the long face? Kangaroos and wallabies follow the same "rule" of cranial evolutionary allometry (CREA) as placentals. Evol. Biol. 42:169-176.

Chen, X., N. Milne, and P. O'Higgins. 2005. Morphological variation of the thoracolumbar vertebrae in Macropodidae and its functional relevance. J. Morphol. 266:167-181.

Christiansen, P. 1999. Scaling of mammalian long bones: small and large mammals compared. J. Zool. 247:333-348.

Cope, E. D. 1891. The Litopterna. Am. Nat. 25:685-693.

Crompton, A., and F. A. Jenkins. 1973. Mammals from reptiles: a review of mammalian origins. Ann. Rev. Earth Planet. Sci. 1:131-155.

D'Agostino, R. B. 1970. Transformation to normality of the null distribution of $g 1$. Biometrika 57:679-681.

Danowitz, M., and N. Solounias. 2015. The cervical osteology of Okapia johnstoni and Giraffa camelopardalis. PloS One 10:e136552.

Danowitz, M., A. Vasilyev, V. Kortlandt, and N. Solounias. 2015. Fossil evidence and stages of elongation of the Giraffa camelopardalis neck. R. Soc. Open Sci. 2:1-12.

Dimery, N. J., R. Alexander, and K. A. Deyst. 1985. Mechanics of the ligamentum nuchae of some artiodactyls. J. Zool. 206:341-351.

Effron, M., L. Griner, and K. Benirschke. 1977. Nature and rate of neoplasia found in captive wild mammals, birds, and reptiles at necropsy. J. Natl. Cancer Inst. 59:185-198.

Eldredge, N., and S. Gould. 1972. Punctuated equilibria: an alternative to phyletic gradualism. In: Models in paleobiology (Schopf, T.J.M., ef.), pp. 82-115. Freeman Cooper, San Francisco.

Endo, H., D. Yamagiwa, M. Fujisawa, J. Kimura, M. Kurohmaru, and Y. Hayashi. 1997. Modified neck muscular system of the giraffe (Giraffa camelopardalis). Ann. Anat. 179:481-485.

Endo, H., O. Hashimoto, H. Taru, K. Sugimura, S.-i. Fujiwara, T. Itou, H. Koie, M. Kitagawa, and T. Sakai. 2013. Comparative morphological examinations of the cervical and thoracic vertebrae and related spinal nerves in the two-toed sloth. Mamm. Study 38:217-224.

Evans, F. G. 1939. The morphology and functional evolution of the atlas-axis complex from fish to mammals. Ann. NY Acad. Sci. 39:29-104.

Forster-Cooper, C. 1911. LXXVIII-Paraceratherium bugtiense, a new genus of Rhinocerotidæ from the Bugti Hills of Baluchistan: Preliminary notice. J. Nat. Hist. 8:711-716.
Fox, H. 1912. Observations upon neoplasms in wild animals in the Philadelphia Zoological Gardens. J. Pathol. Bacteriol. 17:217-231.

Galis, F. 1999. Why do almost all mammals have seven cervical vertebrae? Developmental constraints, Hox genes, and cancer. J. Exp. Zool. 285:1926.

Galis, F., and J. A. Metz. 2003. Anti-cancer selection as a source of developmental and evolutionary constraints. BioEssays 25:1035-1039.

- 2007. Evolutionary novelties: the making and breaking of pleiotropic constraints. Integr. Comp. Biol. 47:409-419.

Galis, F., T. J. Van Dooren, J. D. Feuth, J. A. Metz, A. Witkam, S. Ruinard, M. J. Steigenga, and L. C. Wunaendts. 2006. Extreme selection in humans against homeotic transformations of cervical vertebrae. Evolution 60:2643-2654.

Galis, F., D. R. Carrier, J. Van Alphen, S. D. Van Der Mije, T. J. Van Dooren, J. A. Metz, and C. M. ten Broek. 2014. Fast running restricts evolutionary change of the vertebral column in mammals. Proc. Natl. Acad. Sci. 111:11401-11406.

Gans, C. 1992. Why develop a neck. Pp. 17-21 in W. G. A. Berthoz, and P. P. Vidal, ed. The head-neck sensory motor system. Oxford Univ. Press, New York.

Gellman, K., and J. Bertram. 2002. The equine nuchal ligament 1: structural and material properties. Vet. Comp. Orthop. Traumatol. 15:1-6.

Gould, S. J., and R. C. Lewontin. 1979. The spandrels of San Marco and the Panglossian paradigm: a critique of the adaptationist programme. Proc. R. Soc. Lond. B Biol. Sci. 205:581-598.

Graf, W., C. de Waele, and P. Vidal. 1995a. Functional anatomy of the headneck movement system of quadrupedal and bipedal mammals. J. Anat. 186:55-74.

Graf, W., C. de Waele, P. Vidal, D. Wang, and C. Evinger. 1995b. The orientation of the cervical vertebral column in unrestrained awake animals. II. Movement strategies. Brain Behav. Evol. 45:209-231.

Grand, T. I. 1990. Body composition and the evolution of the Macropodidae (Potorous, Dendrolagus, and Macropus). Anat. Embryol. 182:85-92.

Granger, W., and W. K. Gregory. 1936. Further notes on the gigantic extinct rhinoceros, Baluchitherium, from the Oligocene of Mongolia. Bull. Am. Mus. Nat. Hist. 72:1-73.

Gunji, M., and H. Endo. 2016. Functional cervicothoracic boundary modified by anatomical shifts in the neck of giraffes. R. Soc. Open Sci. 3:1-12.

Gupta, B. B. 1966. Fusion of cervical vertebrae in rodents. Mammalia 30:2529.

Halpert, A. P., F. Jenkins, and H. Franks. 1987. Structure and scaling of the lumbar vertebrae in African bovids (Mammalia: Artiodactyla). J. Zool. 211:239-258.

Hamilton, N. 2016. ggtern: an extension to ggplot2, for the creation of ternary diagrams. R package version 2.1.1. Available at https:// CRAN.R-project.org/package $1 / 4$ ggtern.

Hautier, L., V. Weisbecker, M. R. Sánchez-Villagra, A. Goswami, and R. J. Asher. 2010. Skeletal development in sloths and the evolution of mammalian vertebral patterning. Proc. Natl. Acad. Sci. 107:18903-18908.

Hedges, S. B., J. Marin, M. Suleski, M. Paymer, and S. Kumar. 2015. Tree of life reveals clock-like speciation and diversification. Mol. Biol. Evol. 32:835-845.

Heidweiller, J., A. H. Van Der Leeuw, D. Zweers, and A. Gart. 1992. Cervical kinematics during drinking in developing chickens. J. Exp. Zool. A Ecol. Genet. Physiol. 262:135-153.

Hirasawa, T., and S. Kuratani. 2013. A new scenario of the evolutionary derivation of the mammalian diaphragm from shoulder muscles. J. Anat. 222:504-517.

Hirasawa, T., S. Fujimoto, and S. Kuratani. 2016. Expansion of the neck reconstituted the shoulder-diaphragm in amniote evolution. Dev. Growth Diff. 58:143-153. 
Howell, A. 1930. Myology of the narwhal (Monodon monoceros). Am. J. Anat. 46:187-215.

Hughes, N. C. 2007. The evolution of trilobite body patterning. Ann. Rev. Earth Planet. Sci. 35:401-434.

Huxley, J. S. 1932. Problems of relative growth. Methuen, London.

Huxley, T. H. 1861. On a new species of Macrauchenia (M. boliviensis). Q. J. Geol. Soc. 17:73-85.

Jenkins, F. A. 1969. The evolution and development of the dens of the mammalian axis. Anat. Rec. 164:173-184.

- 1971. The postcranial skeleton of African cynodonts: problems in the early evolution of the mammalian postcranial skeleton. Peabody Mus. Nat. Hist. Bull. 36:1-216.

Johnson, D., and P. O'Higgins. 1996. Is there a link between changes in the vertebral "hoxcode" and the shape of vertebrae? A quantitative study of shape change in the cervical vertebral column of mice. J. Theor. Biol. 183:89-93.

Johnson, D., T. McAndrew, and Ö. Oguz. 1999. Shape differences in the cervical and upper thoracic vertebrae in rats (Rattus norvegicus) and bats (Pteropus poiocephalus): can we see shape patterns derived from position in column and species membership? Journal of Anatomy 194:249253.

Jones, K. E. 2015. Evolutionary allometry of the thoracolumbar centra in felids and bovids. J. Morphol. 276:818-831.

Jones, K. E., and S. E. Pierce. 2016. Axial allometry in a neutrally buoyant environment: effects of the terrestrial-aquatic transition on vertebral scaling. J. Evol. Biol. 29:594-601.

Keshner, E. A. 1990. Controlling stability of a complex movement system. Physical Therapy 70:844-854.

Kingdon, J. 2015. The Kingdon field guide to African mammals. Bloomsbury Publishing, London.

Komsta, L., and F. Novomestky. 2014. moments: moments, cumulants, skewness, kurtosis and related tests. $\mathrm{R}$ package version 0.12. Available at http://CRAN.R-project.org/package=moments.

Krüger, W. 1958. Der Bewegungsapparat. in J.-G. Helmcke, H. van Legerken, and D. Starck, eds. Handbuch der Zoologie, Band 8 (6). Walter de Gruyter \& Co. Verlag, Berlin. 1-176.

Kummer, B. 1959a. Bauprinzipien des Säugerskeletes Georg. Thieme Verlag, Stuttgart, Germany.

- 1959b. Biomechanik des Säugetierskeletts. in J.-G. Helmcke, H. v. Legerken, and D. Starck, eds. Handbuch der Zoologie, Band 8 (6). Walter de Gruyter \& Co. Verlag, Berlin.

Lankester, R. 1908. On certain points in the structure of the cervical vertebrae of the okapi and the giraffe. Proc. Zool. Soc. Lond. 78:320-334.

Lavoué, S., M. Miya, M. E. Arnegard, P. B. McIntyre, V. Mamonekene, and M. Nishida. 2011. Remarkable morphological stasis in an extant vertebrate despite tens of millions of years of divergence. Proc. R. Soc. Lond. B Biol. Sci. 278:1003-1008.

Lecompte, E., C. Denys, and L. Granjon. 2005. Confrontation of morphological and molecular data: the Praomys group (Rodentia, Murinae) as a case of adaptive convergences and morphological stasis. Mol. Phylogenet. Evol. 37:899-919.

Maddison, W. P., and D. R. Maddison. 2011. Mesquite: a modular system for evolutionary analysis. Version 3.10. Available at http://mesquite project.org.

Majoral, M., C. Berge, A. Casinos, and F.-K. Jouffroy. 1997. The length of the vertebral column of primates: an allometric study. Folia Primatol. 68:57-76.

Manfreda, E., P. Mitteroecker, F. L. Bookstein, and K. Schaefer. 2006. Functional morphology of the first cervical vertebra in humans and nonhuman primates. Anat. Rec. B N. Anat. 289:184-194.
Martin, J., V. Martin-Rolland, and E. Frey. 1998. Not cranes or masts, but beams: the biomechanics of sauropod necks. Oryctos 1:113-120.

McMahon, T. 1973. Size and shape in biology. Science 179:1201-1204.

McMahon, T. A. 1975. Using body size to understand the structural design of animals: quadrupedal locomotion. J. Appl. Physiol. 39:619627.

Mitchell, G., D. Roberts, S. Sittert, and J. D. Skinner. 2013. Growth patterns and masses of the heads and necks of male and female giraffes. J. Zool. 290:49-57.

Mobarak, A. and S. Fouad. 1977. A study on Lig. nuchae of the one-humped c (Camelus dromedarius). Anat. Histol. Embryol. 6:188-190.

Müller, J., T. M. Scheyer, J. J. Head, P. M. Barrett, I. Werneburg, P. G. Ericson, D. Pol, and M. R. Sánchez-Villagra. 2010. Homeotic effects, somitogenesis and the evolution of vertebral numbers in recent and fossil amniotes. Proc. Natl. Acad. Sci. 107:2118-2123.

Münkemüller, T., S. Lavergne, B. Bzeznik, S. Dray, T. Jombart, K. Schiffers, and W. Thuiller. 2012. How to measure and test phylogenetic signal. Methods Ecol. Evol. 3:743-756.

Narita, Y., and S. Kuratani. 2005. Evolution of the vertebral formulae in mammals: a perspective on developmental constraints. J. Exp. Zool. B Mol. Dev. Evol. 304:91-106.

Nowak, R. M. 1999. Walker's mammals of the world. The John Hopkins Univ. Press, Baltimore and London.

Osborn, H. F., and C. P. Berkey. 1923. Baluchitherium grangeri, a giant hornless rhinoceros from Mongolia. Am. Mus. Nat. Hist. 78:1-15.

Pagel, M. 1999. Inferring the historical patterns of biological evolution. Nature 401:877-884.

Paradis, E., J. Claude, and K. Strimmer. 2004. APE: analyses of phylogenetics and evolution in R language. Bioinformatics 20:289-290.

Pellionisz, A., B. LeGoff, J. Laczko, and A. Berthoz. 1991. Multidimensional geometry intrinsic to head movements around distributed centers of rotation: a neurocomputer paradigm. Pp. 117-125 in A. Berthoz, W. Graf, \& P. P. Vidal, eds. The head-neck sensory-motor system. Oxford Univ. Press, Oxford, UK.

Perez-Campo, R., M. Lopez-Torres, S. Cadenas, C. Rojas, and G. Barja. 1998. The rate of free radical production as a determinant of the rate of aging: evidence from the comparative approach. J. Comp. Physiol. B 168:149158.

Peterson, B. W., A. J. Pellionisz, J. F. Baker, and E. A. Keshner. 1989. Functional morphology and neural control of neck muscles in mammals. Am. Zool. 29:139-149.

Pinheiro, J., D. Bates, S. DebRoy, D. Sarkar, S. Heisterkamp, B. Van Willigen, and R. Maintainer. 2008. Package "nlme": linear and nonlinear mixed effects models. R package version 3.1-128. Available at http://cran.r-project.org/web/web/packages/nlme/i.

Preuschoft, H., and N. Klein. 2013. Torsion and bending in the neck and tail of sauropod dinosaurs and the function of cervical ribs: insights from functional morphology and biomechanics. PloS One 8(10):1-16.

R Core Team. 2016. R: a language and environment for statistical computing. R Foundation for Statistical Computing, Vienna, Austria.

Randau, M., A. Goswami, J. R. Hutchinson, A. R. Cuff, and S. E. Pierce. 2016. Cryptic complexity in felid vertebral evolution: shape differentiation and allometry of the axial skeleton. Zool. J. Linn. Soc. 178:183-202.

Revell, L. J. 2010. Phylogenetic signal and linear regression on species data. Methods Ecol. Evol. 1:319-329.

. 2012. phytools: an R package for phylogenetic comparative biology (and other things). Methods Ecol. Evol. 3:217-223.

Schmidt, M., and M. S. Fischer. 2009. Morphological integration in mammalian limb proportions: dissociation between function and development. Evolution 63:749-766. 
Schulte, H. v. W., and M. D. F. Smith. 1918. The external characters, skeletal muscles, and peripheral nerves of Kogia breviceps (Blainville). Bull. Am. Mus. Nat. Hist. 38:7-72.

Simmons, R., and R. Altwegg. 2010. Necks-for-sex or competing browsers? A critique of ideas on the evolution of giraffe. J. Zool. 282:6-12.

Slijper, E. 1942. Biologic-anatomical investigations on the bipedal gait and upright posture in mammals, with special reference to a little goat, born without forelegs. Proc. Kon. Ned. Akad. Wetensch. 45:288295.

Slijper, E. J., and R. J. Harrison. 1979. Whales. Cornell Univ. Press, Ithaca, NY.

Smit, T. H. 2002. The use of a quadruped as an in vivo model for the study of the spine-biomechanical considerations. Eur. Spine Journal 11:137144.

Smith, J. M., R. Burian, S. Kauffman, P. Alberch, J. Campbell, B. Goodwin, R. Lande, D. Raup, and L. Wolpert. 1985. Developmental constraints and evolution: a perspective from the Mountain Lake conference on development and evolution. Q. Rev. Biol. 60:265-287.

Solounias, N. 1999. The remarkable anatomy of the giraffe's neck. J. Zool. 247:257-268.

Sturmbauer, C., and A. Meyer. 1992. Genetic divergence, speciation and morphological stasis in a lineage of African cichlid fishes. Nature 358:578581.

Suno-Uchi, N., F. Sasaki, S. Chiba, and M. Kawata. 1997. Morphological stasis and phylogenetic relationships in tadpole shrimps, Triops (Crustacea: Notostraca). Biol. J. Linn. Soc. 61:439-457.

Tacutu, R., T. Craig, A. Budovsky, D. Wuttke, G. Lehmann, D. Taranukha, J. Costa, V. E. Fraifeld, and J. o. P. De Magalhães. 2012. Human ageing genomic resources: integrated databases and tools for the biology and genetics of ageing. Nucleic Acids Res. 41:1027-1033.

Taylor, M. P., and M. J. Wedel. 2013. Why sauropods had long necks; and why giraffes have short necks. PeerJ 1:1-41.

Thompson, D. W. 1917. On growth and form. Cambridge Univ. Press, Cambridge, UK.

Van Den Berg, C. 2000. A dynamical systems approach to movement coordination. Neth. J. Zool. 50:163-178.
Van Der Leeuw, A. 1991. Scaling effects on cervical kinematics in drinking Anatidae. Neth. J. Zool. 42:23-59.

Van Der Leeuw, A. H., R. G. Bout, and G. A. Zweers. 2001. Control of the cranio-cervical system during feeding in birds. Am. Zool. 41:13521363.

Van Schalkwyk, O., J. Skinner, and G. Mitchell. 2004. A comparison of the bone density and morphology of giraffe (Giraffa camelopardalis) and buffalo (Syncerus caffer) skeletons. J. Zool. 264:307-315.

Van Sittert, S. J., J. D. Skinner, and G. Mitchell. 2010. From fetus to adult-an allometric analysis of the giraffe vertebral column. J. Exp. Zool. B Mol. Dev. Evol. 314:469-479.

Van Buren, C. S., and D. C. Evans. 2017. Evolution and function of anterior cervical vertebral fusion in tetrapods. Biol. Rev. 92:608-626.

Varela-Lasheras, I., A. J. Bakker, S. D. van der Mije, J. A. Metz, J. van Alphen, and F. Galis. 2011. Breaking evolutionary and pleiotropic constraints in mammals: on sloths, manatees and homeotic mutations. EvoDevo 2:1-27.

Vidal, P. P., W. Graf, and A. Berthoz. 1986. The orientation of the cervical vertebral column in unrestrained awake animals. Exp. Brain Res. 61:549-559.

Viglino, M., D. Flores, M. Ercoli, and A. Álvarez. 2014. Patterns of morphological variation of the vertebral column in dolphins. J. Zool. 294:267277.

Vislobokova, I. 2013. On the origin of Cetartiodactyla: comparison of data on evolutionary morphology and molecular biology. Paleontol. J. 47:321334.

Witt, J. D., D. W. Blinn, and P. D. Hebert. 2003. The recent evolutionary origin of the phenotypically novel amphipod Hyalella montezuma offers an ecological explanation for morphological stasis in a closely allied species complex. Mol. Ecol. 12:405-413.

Woltering, J. M., and D. Duboule. 2015. Tetrapod axial evolution and developmental constraints; empirical underpinning by a mouse model. Mech. Dev. 138:64-72.

Associate Editor: M. Zelditch Handling Editor: M. Noor

\section{Supporting Information}

Additional Supporting Information may be found in the online version of this article at the publisher's website:

Table S1. Number of specimens, species, and genera included in the study.

Table S2. List of collection specimens included in the study.

Table S3. Data on individual vertebral lengths ( $\mathrm{mm})$, overall cervical spine length $(\mathrm{mm})$, tibial length $(\mathrm{mm})$, and body weight $(\mathrm{kg})$.

Table S4. Scaling analysis for log cervical spine length against log body weight for mammals in general, for the main mammalian clades, and at the (super)familial level.

Table S5. Scaling analysis for log cervical spine length and individual vertebral lengths against log tibial length for mammals in general.

Table S6. Scaling analysis for log cervical vertebral length against log body weight for $\mathrm{C} 1-\mathrm{C} 7$ in mammals in general, the main mammalian clades, and on the (super)familial level.

Table S7. Loadings of the phylogenetic informed PCA of vertebral lengths, overall cervical spine length, and body weight (all log-transformed).

Supplementary Timetree Nexus File 